Published in: McLauchlan A, João E. 2019. Recognising 'learning' as an uncertain source of SEA effectiveness. Impact Assessment and Project Appraisal. 37(3-4): 299-311. https://doi.org/10.1080/14615517.2019.1595940

\title{
Recognising 'learning' as an uncertain source of SEA effectiveness
}

Anna McLauchlan and Elsa João

Address: Civil and Environmental Engineering, University of Strathclyde, Level 5, James Weir Building, G1 1XJ, Scotland

Email: anna.mclauchlan@strath.ac.uk; elsa.joao@strath.ac.uk

\begin{abstract}
SEA's capacity to profile significant environmental effects is thought to help make publicsector decision-making more sustainable. Acknowledgement is growing that 'learning', that links to but transcends individual assessments, is a key source of SEA effectiveness. Such learning is largely positioned as wholesome, moral, as 'good'. The Scottish Parliament went further than the European Commission to require all public bodies to engage with SEA. More than 14 years of evidence - including from the Scottish Government SEA Database (an online registry), a survey and interviews - provides a unique opportunity to study the role of learning in SEA. The paper argues that application of SEA requires systematic reinforcement and maintenance of learning. But the learning fostered by SEA is not guaranteed to prioritise or protect 'environment' - for that to happen SEA must also be embraced as disruptor of the prioritisation of economic goals.
\end{abstract}

Keywords: Strategic environmental assessment, effectiveness, learning, EA registries, access to information, Scotland 
Published in: McLauchlan A, João E. 2019. Recognising 'learning' as an uncertain source of SEA effectiveness. Impact Assessment and Project Appraisal. 37(3-4): 299-311. https://doi.org/10.1080/14615517.2019.1595940

\section{Introduction}

Strategic environmental assessment (SEA) is a process which enables people taking forward plans, programmes and policies to determine, and take account of, the environmental impacts of their actions. At least 40 countries have legislated for some form of SEA, including across the European Union (EU) where an 'SEA Directive' requires SEA to be undertaken of a range of plans and programmes primarily concerned with land use (UN Environment 2018; European Commission 2001). The broader 'goal' of SEA has progressively become sustainable development or sustainability as evidenced within the text of the SEA Directive (European Commission 2001; and also Bina 2007). Importantly, SEA is just one of many practical measures with this goal (Purvis 2004). Legal commitments, including the SEA Directive, often mandate a need for regular reviews of SEA's effectiveness to feed into the development of legislation. Practitioner organisations also sponsor investigations into effectiveness to shape best practice guidelines (e.g. IAIA 2002). The 'learning' that can happen as part of impact assessment is increasingly seen as means to improve effectiveness and thus foster more sustainable outcomes including via institutional change (Sánchez and Mitchell 2017).

Our paper analyses evidence from Scotland to consider the role of learning in SEA. As a result of the SEA Directive, SEA regulations became active across the United Kingdom, including the devolved nation of Scotland, on 24 July 2004. The drive to make Scotland a 'world leader' in SEA led the Scottish Parliament to go further by developing primary legislation, the SEA Act, which came into force from 20 February 2006 (McLauchlan and João 2012 gives an overview). Since then, all public authorities must undertake SEA of all of their plans, programmes and strategies. In Scotland, 'strategies' were equated with 'policies' (Scottish Executive 2006). As the SEA Directive does not apply to 'high level' policy, the inclusion of strategies in the Scottish SEA Act led to it being identified as going even further than the SEA Directive. The self-designation 'leader' is a way to seek legitimacy - it indicates an ambition that other countries should emulate, that is, learn from, Scotland (see Radaelli 2009).

The Scottish administration consciously sought to instigate a noticeable or visible SEA system: setting up an 'SEA Gateway' to field correspondence between organisations taking forward the SEA (responsible authorities), and those with a statutory duty to comment on 
Published in: McLauchlan A, João E. 2019. Recognising 'learning' as an uncertain source of SEA effectiveness. Impact Assessment and Project Appraisal. 37(3-4): 299-311. https://doi.org/10.1080/14615517.2019.1595940

aspects of the SEA process (consultation authorities). The SEA Gateway manages an online register of all SEAs undertaken since 2004, the SEA Database (Scottish Government 2018). Research has previously documented web based environmental assessment registries and their role in making environmental information (publicly) accessible: registries for SEA (combined with other forms of impact assessment) exist in US and Canada. The Scottish SEA Gateway is the only unit of this form in Europe gathering comprehensive information and then making it available online (McLauchlan and João 2005; Odparlik and Köppel 2013).

The availability of information, the commitment for SEA to be undertaken broadly, and the supportive context engendered by the Scottish Government makes Scotland an excellent country-wide case study to consider the role of learning within SEA. Our paper begins by examining the links between learning and effective SEA, justifying our focus on key principles of learning. This is followed by an overview of our approach to researching SEA in Scotland. In relation to the principles of learning we then outline engagement with SEA across Scotland's public sector - where SEA is both present and absent. We then examine how the practice and administration of SEA forms a system. Finally, we reflect on the influence of the continuing prioritisation of economic growth in relation to learning being a source of SEA effectiveness, concluding with an overview of why vigilance about what is learnt is desirable.

\section{2. 'Learning' as the source of SEA effectiveness}

Assessing the 'effectiveness' of impact assessments - processes that are either integrated or in some way associated with decision making - is complex and challenging (Stoeglehner et al 2009). This section charts the developing understanding of SEA effectiveness, making a case that learning that results in institutional change has become the source of what is considered to make SEA effective. It outlines the different forms of learning that SEA fosters. Then provides an overview of how this paper uses key principles of learning to examine evidence of broad institutional change resulting from SEA in the Scottish national context.

Formative understandings of effectiveness first crystallised in international reports on the effectiveness of environmental assessment (Sadler 1996; Sadler and Verheem 1996). These revolve around whether 'the rules' are followed, that is, an assessment is carried out in relation to accepted standards or legal requirements (procedural effectiveness). Alongside 
Published in: McLauchlan A, João E. 2019. Recognising 'learning' as an uncertain source of SEA effectiveness. Impact Assessment and Project Appraisal. 37(3-4): 299-311. https://doi.org/10.1080/14615517.2019.1595940

this, there is concern as to whether assessments are 'fit for purpose' and meet their goals or ambitions (substantive effectiveness). Another issue, evident from these reports but increasingly discussed, is 'transactive' effectiveness, whether resource use (including the economic cost) of an assessment is proportionate to the outcome (Chanchitpricha and Bond 2013).

The categories of procedural and substantive effectiveness have engendered a broad range of criteria to determine to what extent impact assessments are working. Early studies recognised that charting the influence of SEA is complex because "cause and effect is unclear" and “different actors in the process" will view topics differently (Sadler and Verheem 1996, p.19). These complications anticipated the capacity to discuss effectiveness in relation to a particular SEA and a broader SEA system. In many articles (including this one), understandings of SEA are multiple and interwoven: the assessment of an individual plan, programme or policy; the document or 'report' of that assessment; research undertaken on a selection of SEA contexts and/or reports; and, a loose way to label a 'world' of SEA practice and experience (e.g. Marsden 1998; Jha-Thakur et al 2009; Retief 2007). This world includes the activities of people taking forward an SEA, stakeholders (including publics of various kinds), and a broader community of commentators, not least academics and the media. Alongside this, the environmental consciousness SEA aims to promote has the potential to filter into these people's day-to-day lives and other social relations.

Thinking of SEA as having a presence beyond an individual assessment informs the evolving understanding of effectiveness, such as the influence of the assessment on the environment being 'direct' or 'indirect'. These categories overlap with both 'procedural' (rules) and 'substantive' (goals) effectiveness but are arguably largely an expansion of the 'substantive' category. Direct outputs are those that are goal orientated, such as "improving environmental quality and the inclusion of environmental knowledge in decision making" (Stoeglehner et al 2009, p.112). Indirect outputs revolve around "changes in attitudes towards the environment, improved awareness, changes in institutional arrangement and departmental traditions, etc" (Retief 2007, p.87 cited in Stoeglehner et al 2009, p.112). Such indirect outputs can all be understood as stemming from learning that is reinforced and maintained - as a result learning is increasingly thought to be a key source of SEA effectiveness. 
Published in: McLauchlan A, João E. 2019. Recognising 'learning' as an uncertain source of SEA effectiveness. Impact Assessment and Project Appraisal. 37(3-4): 299-311. https://doi.org/10.1080/14615517.2019.1595940

Sánchez and Mitchell (2017) claim that impact assessment (including SEA) can be entirely reconceptualised as a learning process, setting out a taxonomy around three key questions. The first, 'who can learn?' whether this be 'individuals' or 'organisations' including the diverse set of actors discussed above. The second 'what can be learnt?' that takes in 'skills and knowledge', 'new behaviours' and 'norms and values'. The third 'how can learning be achieved?', including via 'formal education', 'experience' and 'public participation' (page 196). Sánchez and Mitchell (2017) directly refer to two specific forms of learning in relation to 'who can learn?', 'organizational learning' and 'social learning'. The former, organizational learning, refers to the extent an organisation embeds learning, both by imitating the practice of others and learning from their own experience (Sánchez-Triana and Ortolano 2001).

The latter, social learning, is subject to a range of interpretations. In the context of Regulatory Impact Assessment (RIA) it has been identified as referring "to large society-wide paradigmatic changes of policy that cannot possibly be induced by RIA" (Radaelli 2009, p.1148); pointing to potential for impact assessment, including SEA, to be transformative of institutional structures (Wallington et al 2007; see also Jiliberto 2011). Webler et al (1995) conceive social learning as a way to inform the development of normative (in that article normative means value driven) criteria to evaluate public participation in impact assessment. Drawing from the formative literature in social psychology and inspired by Habermas (1979), Webler et al (1995, p.445) understand "social change as a process of social learning"; imbuing the concepts of 'change' and 'learning' with a deep optimism to theorise social learning as a process of both "cognitive enhancement and moral development" (italicisation in original).

Generally, the academic literature on learning and impact assessment equates learning with some kind of good outcome (Nilsson 2005; Bina 2007; Jha-Thakur et al 2009; Lobos and Partidario 2014; Ludovico and Fabietti 2018). However, as observed in relation to Environmental Impact Assessment (EIA), learning can "help an organization meet its own goals, but it does not necessarily lead to environmental improvements." (Sánchez-Triana and Ortolano 2001, p.237). Similarly, Jiliberto (2011) briefly critically engages with learning through SEA as a means to foster institutional change. 
Published in: McLauchlan A, João E. 2019. Recognising 'learning' as an uncertain source of SEA effectiveness. Impact Assessment and Project Appraisal. 37(3-4): 299-311. https://doi.org/10.1080/14615517.2019.1595940

The conflation of learning with "goodness" contrasts with how learning is understood in social psychology, where it is conceived as a process rather than a virtue. For example, Albert Bandura's investigations into 'social learning' demonstrate that an aggressive model can encourage people to act more aggressively, whether that model is delivered through TV, films or other media (Bandura et al 1961, 1963; Bandura 1977). Being aggressive is generally thought to be undesirable, that is, not 'good'. In impact assessment literature, many articles also implicitly question the virtue in learning by evidencing that people use impact assessment as a way to rationalise existing decisions (as evidenced in Owens et al 2004) this use is a product of learning just as much as any transformational change considered to make things better.

So, what is learning and how is it used in the context of this paper? Hergenhahn and Olson (2005, p.8, following Kimble 1961) broadly define learning as "a relatively permanent change in behaviour or in behavioural potentiality that results from experience and cannot be attributed to temporary body states such as those induced by illness, fatigue, or drugs." Surveys capture practitioner attitudes to SEA rather than behaviour. As Hergenhahn and Olson (2005, p. 5) state, many prominent learning theorists "agree that the learning process cannot be studied directly; instead, its action can only be inferred from changes in behaviour." Thus, this paper looks at evidence of changes in behaviour in the Scottish context - including from the SEA Database (the registry of all SEA activity), alongside interview and survey data - and relates these to foundational learning principles.

These principles are as follows. For learning to have taken place there must be some evidence of change in behaviour that is relatively permanent, or there must be potential for that change. Clearly, this is complex. It is possible to have learnt something and not perform that learning - a point picked up later in relation to 'Absence of SEA'. Further "the change in behaviour (or behaviour potentiality) results from experience or practice... the experience, or practice must be reinforced; that is, only those responses that lead to reinforcement will be learned" (Hergenhahn and Olson 2005, p.4). In this case 'behaviour potentiality' means that what is learned is not yet enacted but could be in future.

Literature on impact assessment and learning has previously considered individual learning styles but also a form of 'double loop' learning thought to be a "less direct and instrumental outcome of the appraisal exercise" that has "potential to challenge and alter organisational 
Published in: McLauchlan A, João E. 2019. Recognising 'learning' as an uncertain source of SEA effectiveness. Impact Assessment and Project Appraisal. 37(3-4): 299-311. https://doi.org/10.1080/14615517.2019.1595940

norms and values, by questioning, and perhaps changing, the role of framing and learning systems" (Jha-Thakur et al 2009, p.137). This is thought to support impact assessment's role in transforming individuals and institutions in a move towards sustainability or sustainable development (Wallington et al 2007; Jha-Thakur et al 2009). Clearly SEA can promote many different forms of learning in a diverse set of contexts. To provide focus, this paper examines learning by considering evidence of broad institutional change resulting from SEA in the Scottish national context - acknowledging that in psychology how learning operates is an open debate (Hergenhanh and Olson 2005).

\section{Researching SEA in Scotland}

Political considerations are important because they shape knowledge and learning processes and form part of the context for effective SEA (Marsden 1998). SEA being a legal requirement creates an expectation that SEA practice will be informed by government guidance and direction. The devolved Scottish Parliament - that came into being in 1999 has control over a number of issues, including planning and environment, but not energy or broader finances which are dealt with by the UK Parliament. For the first two terms of office (1999-2007) a Labour-Liberal Democrat coalition formed the Scottish Executive. In their second term (2003-2007), they supported the broadening of SEA as part of an agenda to deliver sustainability and environmental justice (Scottish Executive 2003; McLauchlan and João 2011). 'Environment' was prioritised, with SEA guidance suggesting that SEA should focus on environmental rather than social or economic factors - although what 'environment' or 'environmental' means in any given context deserves ongoing vigilance (Whelan and Fry 2011).

The broader context changed in 2007 when the Scottish National Party (SNP) - who seek an independent Scotland in Europe - took power, then claiming a clear majority in 2011 (Herbert et al 2007; 2011). The SNP have supported many broadly social democratic initiatives, such as covering student tuition fees and free medical prescriptions.

Simultaneously, in support of their independence agenda, they are aggressively pro-business, with sustainability and substantive references to the environment initially subsumed within a headline commitment to "sustainable economic growth". 'Environment' in this context is largely associated with 'climate change' and the flagship pledge to reduce carbon emissions by $42 \%$ by 2020 and $80 \%$ by 2050 (Hinde 2016) - although interim targets have been 
Published in: McLauchlan A, João E. 2019. Recognising 'learning' as an uncertain source of SEA effectiveness. Impact Assessment and Project Appraisal. 37(3-4): 299-311. https://doi.org/10.1080/14615517.2019.1595940

consistently missed (BBC News 2015). Since 2015, environmental topics have become part of government direction and these are soon to be linked to the UN sustainable development goals (The Scottish Parliament 2018).

\section{Research approach}

Learning in SEA is investigated through a multi-methods case study of SEA in Scotland. Information was sourced about activity surrounding SEA, people involved with SEA were surveyed and interviewed, and extensive information was drawn from the online registry these different methods are now described. The development of primary legislation generated lots of activity. We drew from previous research charting the history of meetings and events, including those associated with the development of legislation (first documented in McLauchlan 2010). This includes sourcing information from the Scottish Government about a nationwide yearly 'SEA Forum'.

The survey, designed and administered in October 2018, asked practitioners about their engagement with SEA in Scotland. ${ }^{1}$ The survey questions (see Appendix 1) were inspired by research in the Scottish context and literature on impact assessment more generally (as detailed in João and McLauchlan 2018). It was piloted by three people with a background in SEA in Scotland and there were 35 full responses, from Local Authorities (15), statutory Consultation Authorities (10), other public bodies (3), Non-Government Organisations (NGOs) (2), Consultancies (4), and the Scottish Government (1). All respondents to the survey had been engaged with SEA for a period of more than three years, 21 people had ten years' or more experience. Thirteen of 35 respondents had more than one role in relation to SEA during the course of their careers. Thus, responses to the survey captured their diversity of experience rather than just their current role. Many survey questions were open ended and this yielded much information.

Two representatives from each of the three statutory consultation authorities took part in indepth qualitative interviews lasting up to 2-hours. These focussed on their SEA experience and expertise, how their organisation records their SEA activities, and changes in their practice through time. See Appendix 1 for an overview of the questions asked. The semi-

\footnotetext{
${ }^{1}$ Emails were sent to members of the SEA Forum via the Scottish Government, directly to representative of the three statutory consultation authorities and members of Scottish Environment Link (the forum for 35 voluntary environmental organisations). The Law Society of Scotland sent it to their planning law and environmental law sub committees and the Royal Town Planning Institute (RTPI) tweeted information to their followers.
} 
Published in: McLauchlan A, João E. 2019. Recognising 'learning' as an uncertain source of SEA effectiveness. Impact Assessment and Project Appraisal. 37(3-4): 299-311. https://doi.org/10.1080/14615517.2019.1595940

structured approach also allowed us to follow up on emergent topics. Similar information was sourced from the Scottish Government via email, including about the functioning of the SEA Database and the SEA Forum. In this paper, respondents to surveys and interviews are identified by the name of their categories outlined in Table 2. Surveys and interviews are a useful source of information - however, to capture behaviour rather than attitudes it was necessary to understand what SEA had been undertaken.

\section{The Scottish Government SEA Database - a registry of all SEA practice}

As a national review of SEA from 2011 notes, "the level of SEA activity in Scotland is [important] when considering its effectiveness" (SEPA 2011, p.18). The SEA Database (i.e. the registry of SEA activity) intended to contain information about all SEA undertaken in Scotland since 2004. After copying records from the SEA Gateway we tabulated the numbers of plans, programmes and strategies going through defined assessment stages and which organisations had taken them forward, Table $1 .^{2}$ Data was downloaded on 24 July 2018 to capture 14 years of SEA data. However, we noticed that there had been no substantial updates since November 2017, and data had been entered in chunks on particular dates. ${ }^{3}$ After correspondence with the Scottish Government, an update of the database was made available online by 16 October 2018; two days later our spreadsheet was amended to include a further 136 new SEA records and changes to six existing records.

\footnotetext{
${ }^{2}$ Not listed here are a number of records concerning SEAs of plan and programmes that applied to more than one part of the UK (50) and some initiatives from other EU member states (13). This form of intra and international collaboration could be usefully explored in future research in terms of thinking about transboundary SEA systems.

${ }^{3}$ The last record was created 6 July 2018 although there had only been two new records and ten updates since November 2017.
} 
Published in: McLauchlan A, João E. 2019. Recognising 'learning' as an uncertain source of SEA effectiveness. Impact Assessment and Project Appraisal. 37(3-4): 299-311. https://doi.org/10.1080/14615517.2019.1595940

Table 1 - A snapshot of the stages reached by plans and programmes entering the SEA process in Scotland (21 July 04 - 16 October 2018), including plans and programmes that were excluded from SEA as a result of pre-screening (table adapted and updated from McLauchlan and João 2012)

\begin{tabular}{|c|c|c|c|c|c|}
\hline \multirow[t]{2}{*}{ SEA Stage reached } & \multicolumn{5}{|c|}{$\begin{array}{l}\text { The number of plans and programmes that have } \\
\text { reached defined stages of the SEA process }\end{array}$} \\
\hline & Voluntary $^{\mathrm{a}}$ & $\begin{array}{c}\text { Scottish } \\
\text { SEA } \\
\text { Regulations }\end{array}$ & $\begin{array}{c}\text { Scottish } \\
\text { SEA Act } \\
\text { Section } \\
5(3)\end{array}$ & $\begin{array}{c}\text { Scottish } \\
\text { SEA Act } \\
\text { Section } \\
5(4)\end{array}$ & Total \\
\hline Pre-screening statement prepared & & & 84 & 800 & 884 \\
\hline Screening reports in consultation & 1 & 9 & 306 & 110 & 426 \\
\hline Screening reports consulted upon ${ }^{\mathrm{b}}$ & 1 & 9 & 234 & 142 & 386 \\
\hline Scoping reports in consultation & 2 & 2 & 73 & 31 & 108 \\
\hline Environmental reports in preparation or consultation & 4 & 10 & 147 & 57 & 218 \\
\hline $\begin{array}{l}\text { Environmental reports consulted upon (not } \\
\text { 'Adopted') }\end{array}$ & & 4 & 5 & 1 & 10 \\
\hline Adopted plans and programmes ${ }^{c}$ & 6 & 41 & 133 & 71 & 251 \\
\hline 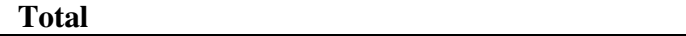 & 14 & 75 & 982 & 1212 & 2283 \\
\hline
\end{tabular}

The SEA Database also enabled us to determine which organisations had done SEA and the types of actions where SEA was routinely applied. We chose to differentiate between: plans and programmes that had been taken forward as a result of the regulations that reflect the SEA Directive only; and, those that were motivated by the SEA Act which is broader than the SEA Directive. Helpfully, these different categories are identified by the SEA Act (and the Scottish Government) as SEA motivated by Section 5(3) and Section 5(4) of the SEA Act. That is why these categories are included in Table 1.

In Scotland, the realisation that such a widespread application of SEA could be costly led to an additional pre-screening stage: where strategies, plans or programmes likely to have "no effect" or "minimal effect, in relation to the environment" (SEA Act Section 7 1(a), (b)) could be 'pre-screened' out of the need to do SEA. This means that all public authorities must engage with at least the pre-screening stage of the process: if only to justify, through prescreening, when a full SEA need not be undertaken. Therefore, analysis of the SEA Database reveals where public authorities have done SEA and can also be used to assess where it has not been done.

Importantly, there were some strange anomalies in the SEA database - pre-screening is driven by Section 5(4) of the SEA Act, but 84 of the 884 pre-screening statements are considered to be motivated by Section 5(3) suggesting erroneously that they were motivated by the provisions of the SEA Directive. This, and the inconsistent updating, means that the 
Published in: McLauchlan A, João E. 2019. Recognising 'learning' as an uncertain source of SEA effectiveness. Impact Assessment and Project Appraisal. 37(3-4): 299-311. https://doi.org/10.1080/14615517.2019.1595940

SEA stages reported in Table 1 should be treated as approximate. A report prepared for SEPA by the consultant Babtie Group (2004) in advance of the SEA Act coming into force, anticipated "that in the region of 2,189 plans, programmes or strategies produced by all sectors may be subject to SEA throughout Scotland" (Babtie 2004, p.14). This is not necessarily a yearly figure; some initiatives are 'one off' and strategic actions might get updated in a range of cycles, for example, two, five, eight or ten years. However, the total figure of 2,283 for 14 years (Table 1) suggests engagement with SEA is not as widespread as expected.

\section{Engagement with SEA}

The broadening of the SEA Directive means that all Scottish public sector bodies should engage with SEA. This, in theory, provides a large number of opportunities for learning. Organisations unfamiliar with forms of policy appraisal or impact assessment have to learn the skills associated with screening, scoping, preparing environmental reports and consultation with expert bodies and the broader public. They have to get to grips with key aspect of SEA such as consideration of alternative, mitigation, cumulative effects and, importantly, the assessment of significance. Understanding what this broadening means in practice requires some estimation of the size of the public sector. This calculation is important because it allows us to compare what organisations have chosen to do SEA (from the database) with all of those others that have elected not to. We did this by sourcing a list of all public bodies from the Office of the Scottish Information Commissioner in 2007 and 2018. Comparing these datasets shows big changes as outlined in Table 2; new public bodies have been created but the overall number has decreased since $2007 .{ }^{4}$

In this paper, the designation 'other public body' largely refers to organisations on that list not included in the categories: Scottish Government, local authority or consultation authority. While 'partnerships' describe the coming together of two or more organisations (often local authorities across a region). Some public bodies have been reconfigured, such as police boards, colleges and the National Health Service (NHS). As part of broader government

\footnotetext{
${ }^{4}$ Many public bodies are part of the government: they may be 'non-departmental' and thus retain some independence or an 'executive agency' that is part of a department but managed separately. The list did not include some bodies that have taken forward SEA that are demonstrably 'public', such as Forestry Commission Scotland or Highlands and Islands Airports Limited erroneously identified as 'private' in McLauchlan 2010 and McLauchlan and João 2012.
} 
Published in: McLauchlan A, João E. 2019. Recognising 'learning' as an uncertain source of SEA effectiveness. Impact Assessment and Project Appraisal. 37(3-4): 299-311. https://doi.org/10.1080/14615517.2019.1595940

restructuring the responsibilities of Communities Scotland - who dealt with housing, homelessness, communities and regeneration - were absorbed into two separate agencies

Table 2 - The number of organisations taking forward SEA in Scotland (21 July 04 - 18 Oct 18) compared with the total number of organisations in each category (table adapted and updated from McLauchlan and João 2012)

\begin{tabular}{|c|c|c|c|c|}
\hline \multirow{2}{*}{$\begin{array}{l}\text { Categories of public } \\
\text { authorities }\end{array}$} & \multicolumn{2}{|c|}{ Number of authorities in each category } & \multicolumn{2}{|c|}{ Engagement with SEA by each group } \\
\hline & Total & $\begin{array}{c}\text { Total that have } \\
\text { engaged with some } \\
\text { aspect of the SEA } \\
\text { process }\end{array}$ & $\begin{array}{l}\text { Pre-screening } \\
\text { statements prepared }\end{array}$ & $\begin{array}{l}\text { SEAs initiated or } \\
\text { completed }\end{array}$ \\
\hline Scottish Government $^{\mathrm{a}}$ & 1 & 1 & 222 & 107 \\
\hline Local authorities $^{\mathrm{b}}$ & 32 & 32 & 570 & 1107 \\
\hline $\begin{array}{l}\text { Consultation } \\
\text { authorities }^{\mathrm{c}}\end{array}$ & 3 & 3 & 48 & 44 \\
\hline $\begin{array}{l}\text { Other public } \\
\text { authorities }{ }^{\mathrm{d}}\end{array}$ & $\begin{array}{c}374(\text { Nov 07) - } 335 \\
\text { (Oct 18) }\end{array}$ & 39 & 40 & 118 \\
\hline Partnership $^{\mathrm{e}}$ & 19 (Unknowable) & 19 & 4 & 23 \\
\hline Total & $\begin{array}{c}429 \text { (Nov 07) - } 390 \\
\text { (Oct 18) }\end{array}$ & 94 & 884 & 1399 \\
\hline
\end{tabular}

Note: Information sourced from Scottish SEA Database (Scottish Government 2018).

a SEA undertaken by Scottish Government includes those SEAs taken forward by the Scottish Executive (The Scottish Parliament has not undertaken SEA directly).

b Defined by Section 2 of the Local Government (Scotland) Act 1994.

c Experts consulted on SEA as identified in the SEA Act, namely Historic Environment Scotland, HES (previously Historic Scotland),

Scottish Natural Heritage (SNH) and the Scottish Environment Protection Agency (SEPA).

$\mathrm{d}$ Other public authorities are all other bodies exempting those referred to above. This section also includes Government Directorates. The total figure of public authorities was derived from a list supplied by the Office of the Scottish Information Commissioner (SIC) Nov 2007 and Oct 2018 - this does not necessarily take in all organisations that can be described as public authorities in the terms provided by the SEA Act (as discussed in McLauchlan and João 2012). The Scottish Government and a number of partnerships and 10 public bodies taking forward SEA were not in the SIC list and not listed and therefore they have been included in the overall total.

e This number of Partnerships undertook SEA but it was not possible to assess how many, beyond those listed, existed at present or had existed.

All public sector organisations should engage with SEA, whereas responses to the survey suggest that "the focus has been upon those that would have been caught under the directive, and more specifically, those relating to land use planning" (consultation authority). This is borne out by the broader data as summarised in Table 2: SEA is largely done by local authorities, and it is most commonly related to land use planning functions. Even where SEA is done of plans, programmes and strategies that lie outside the SEA Directive, it is largely taken forward by local authorities and the Scottish Government, although a great deal of this activity is pre-screening strategies out of the need for SEA.

Most (39 of 58) of the partnerships and other public bodies did SEA only once over the last 14 years. Of those, 16 undertook pre-screening, 12 reached the screening stage and 12 the post-adoption stage. There was fuller engagement from other public bodies and partnerships that would have had to do SEA as a result of the SEA Directive, such as those with a statutory planning function. The following subsections of this paper examine these findings 
Published in: McLauchlan A, João E. 2019. Recognising 'learning' as an uncertain source of SEA effectiveness. Impact Assessment and Project Appraisal. 37(3-4): 299-311. https://doi.org/10.1080/14615517.2019.1595940

in relation to where SEA does (presence), or does not (absence), provide a context for learning.

\section{Presence of SEA}

Local authorities have taken forward the largest number of SEA by sector. These tend to be of key strategic initiatives such as local development plans, local housing strategies and transport strategies - all of which fall under the remit of the SEA Directive. Survey responses indicated that SEA was seen as a continuation of what was already happening as part of local authority planning, for example, "The information was always gathered and analysed. SEA was just formalisation of a process we already carried out" (local authority). In this context, people claim their learning is in the reinforcement of existing skills, where they likely have a high self-efficacy in their capability to complete tasks associated with SEA.

Benefits from SEA were noted, even where no substantive changes were made to strategic initiatives - "new/additional environmental information is often added to the plan or strategy" (consultation authority) or there may be evidence of an "increased focus on environmental variables" (other public body). SEA also has a role in indicating relevant mitigation or modifications including, as one representative of an NGO notes, by inspiring policy wording that recognises the need to be aware of sensitive habitats when planning development. Where plans, programmes or strategies are "environmental in nature" it can have the role of confirming positive outcomes and shaping their environmental benefits though the application of a "robust and consistent methodology" (consultation authority). These statements provide broad evidence of learning. One lengthy reply cited the importance of a supportive context for the reinforcement of learning:

\footnotetext{
"SEAs are viewed as a welcome tool to inform strategic planning across the Council and in our work with partners. We have a State of the Environment Report which is updated every two years. The findings from each edition are reported to our Executive Committee, relevant Partnership Boards and meetings and other interested groups. Annual SEA work and progress is also reported through the Council's governance structures, including elected members and senior management. We have a Corporate SEA Working Group, which has representation from across the Council's services. This helps to ensure buy-in from across the Council. Our Chief Executive also personally signs off all prescreening opinions and screening determinations." (local authority)
}

Capacity in local authorities is also reinforced through a community of practice (Wenger 2000) that transcends administrative borders. Officers in different areas are sometimes doing 
Published in: McLauchlan A, João E. 2019. Recognising 'learning' as an uncertain source of SEA effectiveness. Impact Assessment and Project Appraisal. 37(3-4): 299-311. https://doi.org/10.1080/14615517.2019.1595940

SEA of comparable plans or programmes at roughly the same time - our attendance at the SEA Forum and other SEA events over the years revealed those taking forward SEA of similar initiatives talk to one another about their SEA practice. There are 32 local authorities in Scotland - representatives from 31 of these went to one or more of the nine forums that have taken place between 2009-2018 (there was no forum in 2017) - again making them the largest group taking part (see Figure 1). The majority of local authorities (21) attended five or more forums. The topics discussed at each forum represent current topics of interest echoing the sites of a great deal of SEA application the most recently the focus has been on the changes to Local Development Planning.

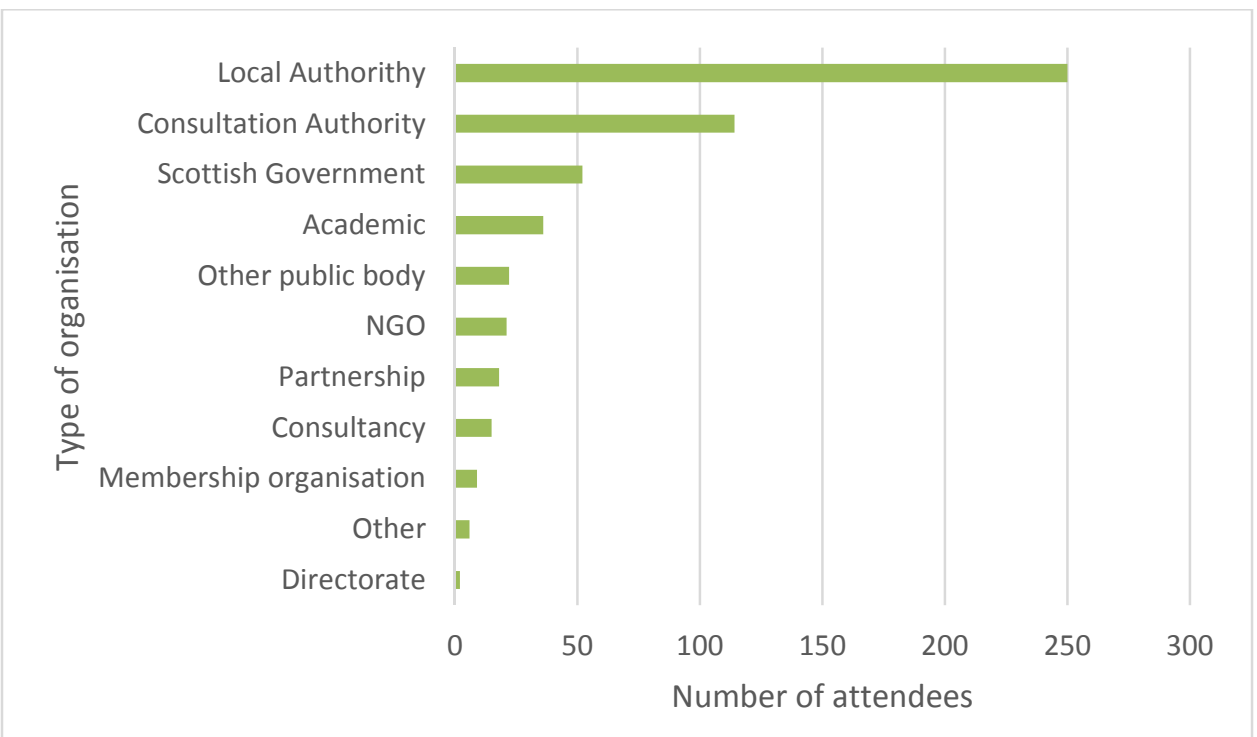

Figure 1 - Attendance of the Scottish SEA Forum between 2009 and 2018, per type of organisation. Note: This is an annual forum but there was no forum in 2017. In total there was an annual attendance of around 60 people. Figure created based on data provided by The Scottish Government.

Most (31 of 34), of the people who responded to our survey attended the SEA Forum at least once - with the majority attending between one and four times - thus our survey captured people who are clearly involved in this broader SEA community. Respondents stated that the SEA Forum was good for peer support, consensus building and finding solutions. One emphasised that as it was "a way of discussing as a profession, as a nation, how we can do this better" while noting the emotional aspects of sharing experience: "As a bonus you get to speak to people who know and feel your pain" (local authority).

The Scottish government also have a widespread and continuing SEA practice. The SEA Gateway itself is a "small administration team who undertakes most of the processing" (Scottish Government). At the time of writing, that comprised three people linked to an 
Published in: McLauchlan A, João E. 2019. Recognising 'learning' as an uncertain source of SEA effectiveness. Impact Assessment and Project Appraisal. 37(3-4): 299-311. https://doi.org/10.1080/14615517.2019.1595940

internal technical team "not directly integrated into the Gateway" that manages the roll out of SEAs (Scottish Government). This institutionalisation of SEA represents further evidence of learning, that is, changes in behaviour that are relatively permanent (Hergenhahn and Olson 2005). Overall, in the last 14 years the Scottish Government have pre-screened 222 and initiated or completed SEAs of 107 plans, programmes and strategies.

Collectively, these include government bills, secondary legislation (and associated consultations), legislation or regulations that are being revised or amended, alongside policies, programmes and a whole host of assessments of funding and grant provision. This is important because legislation and other strategic documents provide a framework for other plans, programmes and strategies and thus potentially have widespread influence. However, one local authority officer indicated there was some danger in thinking SEA might not be needed of a particular plan or programme if SEA has been done of a 'higher level' strategy; SEA is still required because the issues are different and, amongst other things, SEA can trigger mitigation.

Some 'other public bodies' listed in Table 2 are part of the government, including the civil service directorate Marine Scotland and the executive agency Transport Scotland. Energy is not a devolved matter, but Marine Scotland was set up in 2009 to provide information and act as a clearing house in planning matters related to offshore wind. They have taken forward 18 SEAs, a comparatively large number. Offshore wind itself is seen as a key area in relation to the UK provisions of sustainable energy and supports SNP bids for energy and broader independence (although the viability of this is questioned by Toke et al 2013). Thus, it is part of a high-profile statutory planning process with greater potential to be subject to challenge meaning SEA is more likely to be done.

Overall, local authorities and the Scottish Government have the biggest engagement with SEA and the weight of evidence suggests that this is partly the product of a supportive environment alongside a density of practice that acts to constantly reinforce the commitment. However, a large number of the plans, programmes and strategies subject to SEA are concerned with building of infrastructure, business developments, or housing. Local authorities are incentivised to encourage development because (in theory) it bolsters council tax revenues. Evidence from the survey suggests that SEA can influence decisions about sites for development but the extent to which it really acts to question that development is unclear 
Published in: McLauchlan A, João E. 2019. Recognising 'learning' as an uncertain source of SEA effectiveness. Impact Assessment and Project Appraisal. 37(3-4): 299-311. https://doi.org/10.1080/14615517.2019.1595940

(see also Wallington et al 2007). This supports the need for a broader understanding of the wider environmental impact of the present development aims.

\section{Absence of SEA}

Where SEA is absent it provides no concrete opportunities for learning. Large parts of the Scottish public sector have not done SEA despite the requirement for all public bodies, at the very least, to undertake pre-screening of their plans, programmes and strategies (see Table 2). Some have had very limited engagement such as further and higher education institutions (one has pre-screened one plan) or National Health Service (NHS) bodies who have done prescreening twice and screening once. ${ }^{5}$ The NHS in Scotland receives around 12.2 billion in public funding (NHS Scotland 2016) and certainly takes forward a large number of activities with potentially significant environmental impacts - not least related to the disposal of clinical (including radioactive) waste.

This widespread avoidance of SEA may not be conscious, rather it may signal a lack of awareness, not least of the comprehensive need for pre-screening. However, there are no obvious consequences if SEA is not done or done poorly. SEA can be "done it in a tokenistic way or have come to it too late for any practical benefit to result" (local authority). Perhaps, "a few legal cases to challenge authorities that have not carried out SEA" would help? (local authority). Even with broader awareness, SEA legal cases are unlikely: decisions about the lawfulness of actions by public bodies generally happen via judicial review. In Scotland there are legal tests that limit the capacity of someone, or indeed NGOs or interest groups, to bring an action, and for many, costs are likely to be prohibitive (see McLauchlan 2010 chapter 6 for detailed examination of the issues). Claimants' legal costs are only covered in the event of a win - if they lose, they potentially have to pay their own and the other side's costs. As a result, Scotland has been deemed non-compliant with the access to justice requirements of the Aarhus Convention (see Economic Commission for Europe 2017; Christman 2018).

\footnotetext{
${ }^{5}$ Two NHS organisations have pre-screened a health protection plan, corporate framework and one has screened a new infirmary building for the period 2009-13. In some cases representatives have shown an interest, NHS researchers initially saw SEA as a way to integrate 'health' into planning and decision making - but the need for SEA to focus on 'environment' meant the government was directly suggesting that SEA should not consider health's broader social determinants (McLauchlan and João 2012). Another potentially health orientated body, Sportscotland - the national agency for sport undertook SEA of their corporate plan (2007-11) and pre-screened two of their other strategies but there has been no further engagement since 2007.
} 
Published in: McLauchlan A, João E. 2019. Recognising 'learning' as an uncertain source of SEA effectiveness. Impact Assessment and Project Appraisal. 37(3-4): 299-311. https://doi.org/10.1080/14615517.2019.1595940

In Scotland, the initial administrative support for SEA continues via the SEA Forum and the activities of the government and consultation authorities. However, involvement of organisations active in the development of what became the SEA Act - Scottish environmental NGOs, particularly the Royal Society for the Protection of Birds and Friends of the Earth Scotland (FoES) - diminished after the legislation was in force (see McLauchlan 2010; McLauchlan and João 2012). A document on 'environment' "written for the benefit of both new [Members of the Scottish Parliament] and those returning to the Parliament" (Scottish Parliament, Undated) contains no reference to SEA (Barlow et al 2016). There is little engagement by other prominent public facing campaigns, including the Common Weal, a 'think and do tank' campaigning for social and economic equality. ${ }^{6}$ Evidently the commitment to SEA is not comprehensively reinforced, and thus it is not maintained broadly, across the public sector. This diminishes the capacity for widespread learning, and thus transformation change, that in theory could exist as a result of SEA in Scotland.

On balance, many plans, programmes and strategies where SEA has been omitted - such as those taken forward by the licencing boards associated with each local authority - may certainly have "no effect" or "minimal effect, in relation to the environment" (SEA Act Section 7 1(a), (b)). Therefore, they should be pre-screened out. Alongside this, changes in the public sector, including budget cuts, coupled with a lack of reinforcement of the commitment, impacts on the priority afforded to SEA. There is evidence that a wide variety of public sector representatives could see a value in this process and many took part in SEA training, including some organisations that have not taken forward SEA (João and McLauchlan 2014). As previously stated, it is possible to learn something and not perform that learning. Thus, many people have learnt the basics of SEA, although the absence of SEA in many sectors suggests some of this has not yet resulted in the performance of changes to behaviour.

Private sector organisations also potentially take forward public plans, programmes or strategies, but the only wholly private organisation to do SEA (to screening) in 14 years of records is 'The Scottish Mountain Bike Development Consortium'. Their National Mountain

\footnotetext{
${ }^{6}$ In particular, only one of their 101 key ideas refers to 'environment' - “\#56 Embed environmental performance factors into every element of policy development". No reference is made to SEA and this 'key idea' comes under the broader heading of 'national infrastructure'; a spokesperson said that several of their policy briefs refer to environment and they follow the stance of the Scottish Green Party (Common Weal, pers. comm. 5 Nov 2018).
} 
Published in: McLauchlan A, João E. 2019. Recognising 'learning' as an uncertain source of SEA effectiveness. Impact Assessment and Project Appraisal. 37(3-4): 299-311. https://doi.org/10.1080/14615517.2019.1595940

Biking Framework seems relatively inconsequential in comparison to the potential remit of the SEA Directive in areas such as agriculture or energy transmission. SEA can only provide substantive opportunities for learning when it is being done. Thus, further investigation is needed of other sectors where SEA is potentially absent. To study learning in relation to the evidence of institutional change generated by SEA, we now consider how documenting SEA practice and making it available generates and reinforces a system.

\section{A system made through practice}

Decisions about which environmental effects are significant are fundamental to SEA. An assessment of significance determines whether or not SEA is undertaken, either as a result of the screening process or also, in Scotland, pre-screening. Understandings of significance also shape what is 'scoped into' any given assessment. Learning how to write in a way that communicates what is or is not significant can prioritise the environment (arguably good), can generate efficiency by ensuring SEA is done only when necessary (arguably good too), but could also engender systemic avoidance of SEA where SEA is needed (potentially problematic). Learning how to do this form of writing happens by observing and imitating models, including SEA literature.

Survey respondents, with a possibility of choosing more than one category, were asked what literature they regularly consulted; environmental reports (28) were most frequently selected, followed by guidance (27), legislation (18) then academic literature (8). ${ }^{7}$ When asked what SEA literature survey respondents found useful, Scottish government guidance was most often cited (23 of 53, again more than one category could be picked) alongside guidance made available by the consultation authorities (14 of 53). This demonstrates the influential role of consultation authorities and the Scottish Government in curating (setting a framework) for the learning that can happen through SEA, as is evidenced by their active engagement in the SEA Forum. This co-production of knowledge is reinforced by the three consultation authorities and the Scottish government meeting every three or four months to discuss SEA practice, guidance and plan the SEA Forum.

\footnotetext{
7 'Other' literature was also chosen by nine people, which they then reported included case law, grey literature, state of the environment reports, in-house reporting, planning magazines and updates via professional organisations such as the Royal Town Planning Institute (RTPI).
} 
Published in: McLauchlan A, João E. 2019. Recognising 'learning' as an uncertain source of SEA effectiveness. Impact Assessment and Project Appraisal. 37(3-4): 299-311. https://doi.org/10.1080/14615517.2019.1595940

In Scotland the consultation authorities must offer an opinion on screening and scoping. They are also sent, but not required to respond to, material related to pre-screening and environmental reports. In practice, evidence from the SEA Database and interviews indicates that the consultation authorities manage the pre-screening material and environmental reports in a similar way to other documents, often registering a 'no response' for pre-screening but routinely commenting on environmental reports (see also McLauchlan 2010; McLauchlan and João 2012).

Consultation authorities need not look at associated planning documents unless they form part of another statutory consultation process, such as Local Development Plans. This limits the capacity for learning from SEA to feed into broader non-statutory planning processes. When SEA first came into being in Scotland, statutory consultation on SEA documents could happen separately from its related plan - now consultation authorities ensure they are both undertaken by the same person. Consultation authorities only look at particular topics (e.g. SEPA review air, water, soil and human health) but replies are shared between them, and in some cases there is discussion about particular SEA reports, to try to improve the consistency of advice.

Consultation authorities keep their own records for administrative purposes using their own data management systems - meaning they have up-to-date records to work from. One consultation authority representative stated that an added advantage of having their own system was that where a staff member was unfamiliar with the context and they had "to pick up a case from scratch [they] can go in there and they can find out who dealt with it previously and its background and history."

At present we have no information about whether or how the SEA Database is used by the public. However, the lack of consistent updating means it cannot be used to follow 'live' SEA activity - impacting on its capacity to support statutory public participation as Odparlik and Köppel (2013) suggest. Certainly, interviewees identified that the SEA Database has been used by local authorities as a way to show examples to others of where SEA is and is not needed. As a result, the SEA Database can act as guidance to others to sanction what is written out of SEA - i.e. earlier decisions set precedents. 
Published in: McLauchlan A, João E. 2019. Recognising 'learning' as an uncertain source of SEA effectiveness. Impact Assessment and Project Appraisal. 37(3-4): 299-311. https://doi.org/10.1080/14615517.2019.1595940

This is important because interviews and survey responses suggest plans, programmes and strategies could be written into, and thus be subject to, SEA unnecessarily. Drawing from traditions in business, planning documents in the public sector often contain broader 'mission' or 'vision' statements that can overemphasise ambitions. As one local authority officer stated: "you would think every policy the council wrote was going to change the world." On the other hand, environmental impacts can be downplayed or not represented in any way, meaning plans, programmes and strategies that would potentially benefit from SEA are excluded from this process.

For example, many plans pre-screened out of SEA are 'economic' such as procurement plans (11 pre-screened, three reaching screening) and economic strategies (of 34 entering the SEA process, 14 were pre-screened and in 14 years only two reached the final stages of environmental report and post adoption respectively). All local authorities take forward economic strategies but 17 of 32 have not engaged even with the pre-screening process. These economic plans relate to the management of public sector funding and thus would be expected to have significant environmental impacts - thus arguably SEA should be done of each plan renewal. Whether or not SEA should be applied here is muddied by the Scottish SEA Act not applying to "financial or budgetary plans and programmes" (Section 4(3)(b)).

In these cases, once a particular type of plan, programme or strategy has been written out (pre-screened or screened out) of SEA a number of times, other authorities no longer do SEA for those types of activities. This generates a situation where the name of the plan, rather than a clear consideration of its content, creates a pattern that is both inclusive and exclusive. 'Writing out' is a capacity that is learned and supported by the structure of the database. However, the SEA Database also documents this activity thus making it transparent $-\mathrm{a}$ hugely important function. SEA activity is both recorded and influenced by the presence of the SEA Database - again, further thought is needed about how this can be shaped to increase access to relevant information and communicate an understanding of how SEA in Scotland is changed by its existence.

\section{The rhetoric and reality of what is 'normative' - SEA as an intervention into an ideology of economic prioritisation?}


Published in: McLauchlan A, João E. 2019. Recognising 'learning' as an uncertain source of SEA effectiveness. Impact Assessment and Project Appraisal. 37(3-4): 299-311. https://doi.org/10.1080/14615517.2019.1595940

The learning SEA can bring about is mediated by the broader ideological landscape and what people perceive of as SEA's goal. Increasingly SEA literature considers this to be sustainability. Sustainability, and the sister concept sustainable development, is often identified as 'normative'. This is confusing because it suggests that the norm is sustainability (Nilsson 2004; a critical stance is articulated by Connelly and Richardson 2005). Arguably SEA, and its rhetorical prioritisation of the environment, is an intervention which attempts to challenge norms and transform them (as discussed in Jha-Thakur et al 2009). Such norms are those that emphasise the need for constant economic growth in support of broader prosperity: a world view maintained through ontogenetic learning (learning during a lifetime) that is potentially unchallengeable. This impacts on people theorising about SEA as much as those closely involved in SEA practice - academia is also subject to seemingly unchallengeable processes of marketisation.

These concerns about the potential influence of SEA were evident in responses to a survey question about what was understood by 'effective SEA'. Most (11) stated that it meant that SEA was an integral part of plan-making, running alongside it from the beginning. Three suggested that it was about ensuring policy and planning choices are made sustainably. Several responses, both to the survey and interviews, specifically indicated that separating out 'environment' made SEA in Scotland less effective at influencing plan-making than the broader UK framework of sustainability appraisal. However, this could contradict the need to demonstrate "a clear awareness of the environment ... as opposed to a very narrow or exclusively social/economic view of the issue at hand" (consultation authority).

Integration may be difficult to achieve. As evidenced in Section 2 of this paper: "Quite often the goal of the plan is in conflict with environmental interests, so there is officially little scope for changing its direction to make it more environmentally considerate, as that is not the role of SEA" (consultation authority). Others stated that SEA was used to ameliorate this conflict, motivating rewrites to planning guidance documents to attempt to counter the detrimental impact of policies supporting "sustainable economic growth" (local authority). However, this countering may be ineffective because there is a danger that plans and related guidance are ignored in the face of economic prioritisation through local level planning allocation decisions (Kaminer 2018). 
Published in: McLauchlan A, João E. 2019. Recognising 'learning' as an uncertain source of SEA effectiveness. Impact Assessment and Project Appraisal. 37(3-4): 299-311. https://doi.org/10.1080/14615517.2019.1595940

Further, some questioning of the claims of economic benefits are required - is the prioritising of infrastructure together with house building going to generate broader economic benefit in the longer term? This is particularly problematic because the character of much of what is built does not seem to relate to a demonstrable need. This also signals a broader danger of prioritising the economic value SEA might add to planning processes and the potential to conflate 'efficiency' and 'effectiveness' (Morrison-Saunders et al 2014, following Oosterhuis 2007). This could instrumentalise SEA as a tool for economic ends and stifle the ambition to prioritise environment.

\section{Conclusions}

SEA is more than a process applied to a particular plan, programme or strategy (or indeed policy) - it, and the learning it potentially fosters, extends to the multiple but related applications of SEA that make up a world of SEA practice and experience. This means that SEA can provide a large number of opportunities for learning; by people taking forward the assessments, those consulted on them, commentators (including academics and the media) and a broader public. The commitment to SEA in Scotland was intended to apply widely across the public sector. Our investigation indicates that this has fostered institutional changes some of which are relatively permanent - supporting the claim that some aspects of SEA in Scotland are 'world leading'.

Such change was most evident in the Scottish government itself, who have a team dedicated to taking forward SEA of policy and draft legislation. The Scottish Government SEA Database, the registry, can be used by anyone with online access. This provides models of SEA practice, and with some processing, it can give broader understandings of where and what SEA is being done. Thus, it can be mined for evidence of the development of SEA practices. However, interest from people (in this case us, as academics) was needed to ensure the information provided was up to date. The lack of updating impacts on the SEA Database's ability to be a source of public information about SEA 'as it happens'.

Where SEA was reported as really 'working' this seems to be down to a supportive community of practice. Some parts of local government have formalised existing planning practices, using SEA as a means to document environmental impacts of their actions. The Scottish Government sponsored SEA forum supports practice through collective sharing of 
Published in: McLauchlan A, João E. 2019. Recognising 'learning' as an uncertain source of SEA effectiveness. Impact Assessment and Project Appraisal. 37(3-4): 299-311. https://doi.org/10.1080/14615517.2019.1595940

information and experience. Statutory consultation authorities required to offer opinions on SEA, have also developed approaches to managing consultation. However, there was less uptake of SEA by organisations not already familiar with the requirements of impact assessment. This means that large parts of the Scottish public sector have not engaged with SEA despite it being a legal duty. Clearly this absence diminishes the potential for learning through SEA. It motivates a deeper need to consider the absence of SEA, in particular in sectors such as agriculture which have demonstrably significant environmental effects.

SEA can have a role in challenging and changing how decisions are made. However, when plans are put into practice 'wins' from SEA can be lost - vigilance is needed but also an ongoing questioning of prioritising uncertain means of achieving economic growth, for example in the house building sector, questioning whether the actions taken can really achieve their intended social benefits. That said, SEA is just one of many practical measures aiming for sustainability or sustainable development; organisations may not be doing SEA but can be promoting consideration of the environment in other ways. In the face of rival priorities in the public sector, 'environment' must be continually present, whilst maintaining a deep awareness of the potentially competing understandings of what this concept can mean.

Literature on learning in impact assessment largely positions learning as a virtue rather than merely a process. By extension, this implies that learning through SEA can prompt positive transformation of institutions. Increasingly, commentators suggest that such transformation may be what makes SEA effective in fostering sustainable development or sustainability. This paper recognises that learning can take forms that are not considered to be beneficial. Observation and imitation, key parts of learning, enable SEA to happen. However, they can also generate and reify processes of SEA administration that can lead to avoidance of SEA where environmental impacts may be significant. Those processes are still learning. Overall, this leads us to conclude that learning is an uncertain source of SEA effectiveness.

Recognising this uncertainty is not to undermine the possibility for SEA, in its myriad forms, to promote potentially beneficial learning - but what is learnt and the effects of such learning requires greater thought. 
Published in: McLauchlan A, João E. 2019. Recognising 'learning' as an uncertain source of SEA effectiveness. Impact Assessment and Project Appraisal. 37(3-4): 299-311. https://doi.org/10.1080/14615517.2019.1595940

\section{References}

Babtie Group. 2004. Scottish Environment Protection Agency: Identifying the Potential Number of Strategies, Plans and Programmes Subject to Environmental Assessment in Scotland. Glasgow: Babtie Group Limited.

Bandura, A. 1977. Social Learning Theory. New Jersey: Prentice-Hall, Inc.

Bandura A, Ross D, Ross SA. 1961. Transmission of aggression through imitation of aggressive models. Educational Psychology in context. Readings for future teachers. SAGE Publications, Thousand Oakes, 57-66.

Bandura A, Ross D, Ross SA. 1963. Imitation of film mediate aggressive models. Journal of Abnormal \& Social Psychology, 66(1): 3-11.

Barlow D, O'Brien F, Edwards T, Kenyon W, Rehfisch A, Reid A. 2016. SPICe Briefing Environment: Subject Profile. 16/42. Edinburgh: The Scottish Parliament. Available online: http://www.parliament.scot/ResearchBriefingsAndFactsheets/S5/SB_16-

42_Environment_Subject_Profile.pdf

BBC News. 2015. Scotland misses greenhouse emission target. 9 June. https://www.bbc.co.uk/news/uk-scotland-scotland-politics-33058391

Bina O. 2007. A Critical review of the dominant lines of argumentation on the need for Strategic Environmental Assessment. Environmental Impact Assessment Review, 27: 585606.

Christman B. 2018. (Non)-developments in environmental justice in Scotland. Environmental Law Review, 20(2): 69-73.

Connelly S, Richardson T. 2005. Value-driven SEA: Time for an environmental justice perspective? Environmental Impact Assessment Review, 25(4): 391-409.

Chanchitpricha C, Bond A. 2013. Conceptualising the effectiveness of impact assessment processes. Environmental Impact Assessment Review, 43: 65-72.

Economic Commission for Europe. 2017. Meeting of the Parties to the Convention on Access to Information, Public Participation in Decision making and Access to Justice in Environmental Matters. Sixth session Budva, Montenegro, 11-13 September 2017. Item 7 (b) of the provisional agenda Procedures and mechanisms facilitating the implementation of the Convention: compliance mechanism. Draft decision VI/8k concerning compliance by the United Kingdom of Great Britain and Northern Ireland with its obligations under the Convention. Available online:

https://www.unece.org/fileadmin/DAM/env/pp/mop6/Documents_aec/ECE.MP.PP.2017.30_ aec.pdf

European Commission. 2001. Directive 2001/42/EC of the European Parliament and of the Council of 27 June 2001 on the assessment of the effects of certain plans and programmes on the environment. Official Journal of the European Communities, L 197, 21 July 2001. 
Published in: McLauchlan A, João E. 2019. Recognising 'learning' as an uncertain source of SEA effectiveness. Impact Assessment and Project Appraisal. 37(3-4): 299-311. https://doi.org/10.1080/14615517.2019.1595940

Stoeglehner G, Brown AL, Kørnøv L B. 2009. SEA and planning: 'ownership' of strategic environmental assessment by the planners is the key to its effectiveness. Impact Assessment and Project Appraisal, 27(2): 111-120.

Habermas J. 1979. Communication and the Evolution of Society. Boston, MA: Beacon.

Herbert S, Burnside R, Earle M, Edwards T, Foley T, Mciver I. 2007. Election 2007. SPICe briefing. 8 May 2007. 07/21.

Herbert S, Burnside R, Earle M, Liddell G, Mciver I. 2011. Election 2011. SPICe briefing. 10 May 2011. 11/29.

Hergenhahn B, Olson M. 2005. An introduction to theories of learning. London: Pearson Prentice Hall.

Hinde D. 2016. It's our environment: two terms of SNP environmental policy. Scottish Affairs, 25(1): 83-102.

IAIA. 2002. Strategic Environmental Assessment: Performance Criteria. Special Publication Series No.1. http://www.iaia.org/uploads/pdf/sp1.pdf

Jha-Thakur U, Gazzola P, Peel D, Fischer T, Kidd S. 2009. Effectiveness of strategic environmental assessment - the significance of learning. Impact Assessment and Project Appraisal, 27(2): 133-144.

Jiliberto R. 2011. Recognizing the institutional dimension of strategic environmental assessment, Impact Assessment and Project Appraisal, 29(2): 133-140.

João E, McLauchlan A. 2011. Strategic Environmental Assessment as a tool to contribute to high-level policy objectives. Journal of Environmental Assessment, Policy and Management, 13(1): 1-8.

João E, McLauchlan A. 2014. Would you do SEA if you didn't have to? - Reflections on acceptance or rejection of the SEA process. Impact Assessment and Project Appraisal, 32(2): 87-97.

João E, McLauchlan A. 2018. Strategic environmental assessment (SEA) in Scotland: An independent report drawn from a survey. (Unpublished.)

Kaminer, T. 2018. Stealth Policy-Making in Planning and the 'Productive' Imbroglio of Governance. Paper presentation at the Royal Geographical Society Conference, Cardiff. 30 August.

Kimble G A. 1961. Hiligard and Marquis' conditioning and learning. Second edition. Englewood Cliffs. NJ: Prentice Hall.

Lobos V, Partidario M. 2014. Theory versus practice in Strategic Environmental Assessment (SEA). Environmental Impact Assessment Review, 48: 34-46. 
Published in: McLauchlan A, João E. 2019. Recognising 'learning' as an uncertain source of SEA effectiveness. Impact Assessment and Project Appraisal. 37(3-4): 299-311. https://doi.org/10.1080/14615517.2019.1595940

Ludovico D, Fabietti V. 2018. Strategic Environmental Assessment, key issues of its effectiveness. The results of the Speedy Project. Environmental Impact Assessment Review, 68: 19-28.

Marsden S. 1998. Importance of context in measuring the effectiveness of strategic environmental assessment. Impact Assessment and Project Appraisal, 16(4): 255-266.

McLauchlan A, João E. 2005. An independent body to oversee strategic environmental assessment in Scotland: bureaucratic burden or efficient accountable administration? A preliminary report prepared for Scottish Environment Link.

McLauchlan A. 2010. Environmental Justice as a Policy Objective. Unpublished PhD Thesis. Department of Civil Engineering. Glasgow: University of Strathclyde.

McLauchlan A, João E. 2011. The utopian goal of attempting to deliver environmental justice via Strategic Environmental Assessment. Journal of Environmental Assessment, Policy and Management, 13(1): 129-158

McLauchlan A, João E. 2012. The inherent tensions arising from attempting to carry out strategic environmental assessments on all policies, plans and programmes. Environmental Impact Assessment Review, 36: 23-33.

Morrison-Saunders A, Pope J, Gunn J, Bond A, Retief F. 2014. Strengthening impact assessment: a call for integration and focus. Impact Assessment and Project Appraisal, 32(1): $2-8$.

National Health Service (NHS). 2016. NHS in Scotland 2016. Audit Scotland. October 2016. Available: http://www.audit-

scotland.gov.uk/uploads/docs/report/2016/nr_161027_nhs_overview.pdf (accessed 15 November 2018).

Nilsson, M. 2005. Learning, Frames, and Environmental Policy Integration: The Case of Swedish Energy Policy. Environment and Planning C: Government and Policy, 23(2): 207226.

Odparlik L, Köppel J. 2013. Access to information and the role of environmental assessment registries for public participation. Impact Assessment and Project Appraisal, 31(4): 324-331.

Oosterhuis F. 2007. Costs and benefits of the EIA Directive [accessed 2018 Dec 13].

Available from:

http://ec.europa.eu/environment/eia/pdf/Costs\%20and\%20benefits $\% 20$ of $\% 20$ the $\% 20$ EIA $\% 2$

0Directive.pdf

Owens S, Rayner T, Bina O. 2004. New agendas for appraisal: reflections on theory, practice and research. Environment and Planning A, 36: 1943-1959.

Purvis M. 2004. Geography and Sustainable Development, in, Purvis M, Grainger A (Eds) Exploring Sustainable Development: Geographical Perspectives, pp.33-49. London; Sterling, VA: Earthscan Publications Limited. 
Published in: McLauchlan A, João E. 2019. Recognising 'learning' as an uncertain source of SEA effectiveness. Impact Assessment and Project Appraisal. 37(3-4): 299-311. https://doi.org/10.1080/14615517.2019.1595940

Radaelli, C M. (2009) Measuring policy learning: regulatory impact assessment in Europe, Journal of European Public Policy, 16(8): 1145-1164.

Retief F. 2007. Effectiveness of strategic environmental assessment SEA) in South Africa. Journal of Environmental Assessment Policy and Management, 9(1): 83-101.

Sadler B. 1996. Environmental Assessment in a Changing World: Evaluating Practice to Improve Performance. Final Report of the International Study of the Effectiveness of Environmental Assessment. Ottawa, Canadian Environmental Assessment Agency and International Association for Impact Assessment.

Sadler S, and Verheem R. 1996. Strategic Environmental Assessment: Status, Challenges and Future Direction. Ministry of Housing, Spatial Development and the Environment, The Netherlands.

Sánchez L E, Mitchell R. 2017. Conceptualizing impact assessment as a learning process. Environmental Impact Assessment Review, 62: 195-204.

Sánchez-Triana E, Ortolano L. 2001. Organizational learning and environmental impact assessment at Colombia's Cauca Valley Corporation. Environmental Impact Assessment Review, 21(3): 223-239.

Scottish Executive. 2003. A Partnership for a Better Scotland: Partnership Agreement. https://www2.gov.scot/Resource/Doc/47095/0025772.pdf

Scottish Executive. 2006. Strategic Environmental Assessment Toolkit. https://www2.gov.scot/resource/doc/148434/0039453.pdf

Scottish Government. 2018. SEA Database holding all Scottish SEA material since July 2004. https://www2.gov.scot/Topics/Environment/environmental-assessment/sea/SEAG

SEPA [Scottish Environment Protection Agency]. 2011. The Scottish Strategic Environmental Assessment Review. Stirling: The Scottish Environmental Protection Agency. Available online: https://www.sepa.org.uk/media/27555/sea-review-_mainreport_july2011.pdf

The Scottish Parliament (Ishani Erasmus). 2018. National Outcomes Consultation 2018: What are National Outcomes. Available online: https://digitalpublications.parliament.scot/ResearchBriefings/Report/2018/4/12/NationalOutcomes-Consultation-2018\#What-are-National-Outcomes-

The Scottish Parliament. Undated. SB 16-42 Environment: Subject Profile. Available online: http://www.parliament.scot/parliamentarybusiness/99609.aspx

Toke D, Sherry-Brennan F, Cowell R, Ellis G, Strachan PA. 2013. Scotland, renewable energy and the independence debate: Will head or heart rule the roost? Political Quarterly, 84(1), 61-70. 
Published in: McLauchlan A, João E. 2019. Recognising 'learning' as an uncertain source of SEA effectiveness. Impact Assessment and Project Appraisal. 37(3-4): 299-311. https://doi.org/10.1080/14615517.2019.1595940

UN Environment 2018. Assessing Environmental Impacts- A Global Review of Legislation, Nairobi, Kenya. https://europa.eu/capacity4dev/unep/documents/assessing-environmentalimpacts-global-review-legislation

Wallington T, Bina O, Thissen, W. 2007. Theorising strategic environmental assessment: fresh perspectives and future challenges. Environmental Impact Assessment Review, 27, 569584.

Webler T, Kastenholz H, Renn O. 1995. Public participation in impact assessment: A social learning perspective. Environmental Impact Assessment Review, 15(5): 443-463.

Whelan J, Fry J. 2011. The lack of SEA to support agri-environmental objectives in Ireland's rural environment protection scheme. Journal of Environmental Assessment Policy and Management, 13(1): pp.101-127.

Wenger É. 2000. Communities of practice and social learning systems. Organization, 7(2): 225-246.

\section{Appendix 1 - Survey and Interview Questions}

Survey questions (the ones with a (*) were also asked at interview):

- What type of organisation do you work for?

- Your organisation name (optional)

- What is your role within your current organisation? $(*)$

- Your name (optional)

- Your email (optional)

- What main SEA topics are most relevant to your job (can pick more than one)?

- What is your most recent SEA experience?

- Have you had more than one role in relation to SEA? (*)

- If yes, please briefly describe other roles you have undertaken (not previously listed)

- How long have you worked in SEA? (please specify the number of months or years) (*)

- Thinking back on the SEAs that you have been involved in, how would you describe the context and decision-making situation in which the SEAs were carried out? For example, how open were politicians and planners to new environmental information, how were planning solutions decided, did the SEA have an impact on these? (*)

- What were the key changes made to the plan, programme or strategy as a result of the SEA (reflect on a specific examples or a series of examples that seem indicative)?

- How would you describe the purpose of SEA? (*)

- How would you measure or evaluate that SEA is achieving that purpose? (*)

- There is a lot of discussion about the effectiveness of SEA. What do you understand by "effective SEA"? (*)

- What would help improve the SEA process in Scotland? (*)

- What impact has SEA had on your organisation? For example, new staff, staff roles changing, changes to working practices. $(*)$

- Have you ever attended the SEA forum since it started in 2009?

- How many SEA forums have you attended? Please note: The first forum took place on 25 September 2009 and there was no forum in 2017.

- What do you get out of attending or being involved with the SEA forum? (*) 
Published in: McLauchlan A, João E. 2019. Recognising 'learning' as an uncertain source of SEA effectiveness. Impact Assessment and Project Appraisal. 37(3-4): 299-311. https://doi.org/10.1080/14615517.2019.1595940

- What literature do you regularly read that relates to SEA?

- Which guidance has been most useful to you? Which are your top three (even if no longer available or in draft version)?

- Please describe how you use the academic literature?

- Have you undertaken any formal training in SEA? (this could be a specific training course of something that was part of a degree programme)

- If yes, what training have you had?

- How did that training influence how you engage with SEA?

- Any other comments?

Interview questions (in addition to the asterisk questions above, the following were just asked just at interview):

- How has your organisation changed since the commitment to undertake SEA first became active?

- How do you use the SEA database?

- What is your involvement in the SEA forum?

- What data management do you do at your organisation with regards to SEA? (in-depth interviews in the offices of consultation authorities enabled the first author to explore this topic in detail)

- What do you think will be the impact of Brexit in SEA in Scotland?

\section{Acknowledgements}

Thanks to the people who piloted the SEA in Scotland survey - their input greatly helped to focus our questioning - and those who responded to the survey, we were impressed with their eloquent communication and the richness of information provided. A special thanks to the consultation authorities and selected representative of local authorities and other public bodies that participated in interviews - this gave us a far fuller understanding of aspects of the changing SEA landscape. Thanks to staff at the SEA Gateway for proving data about the SEA Forum and for updating the SEA Database. The comments of the two anonymous referees and Andrew Thompson were exceptionally helpful in shaping our ideas. Rachel Homer and Andy Turner of the University of Leeds respectively assisted in a preliminary data analysis and looking at options for data download. This research was made possible by the ongoing support of Margaret McLauchlan. 